chemical degradation, which can distinguish between a $3^{\prime}: 5^{\prime}$ - and $2^{\prime}: 5^{\prime}$-phosphodiester linkage ${ }^{10}$.

D. M. Brown

D. I. Magrath

A. H. NeILson

A. R. TODD

University Chemical Laboratory, Cambridge.

Sloan-Kettering Institute for Cancer Research, New York. May 16.

${ }^{1}$ Brown and Todd, J. Chem. Soc., 52 (1952).

"Brown and Todd, in "The Nucleic Acids", edit. by Chargaff and Davidson, 1, 409 (Academic Press, New Ýork, 1955).

${ }^{3}$ Brown and Todd, $J$. Chem. Soc., 2040 (1953). Lipkin, Talbert and Bender, Amer Chem. Soc. 73,1626 (1951).

${ }^{5}$ Michelson, Szabo and Todd, $J$. Chem. Soc. (in the press).

${ }^{6}$ Baer and Kates, J. Biol. Chem., 175, 79 (1948); 185, 615 (1950).

${ }^{7}$ Long and Maguire, Biochem. J., 54, 612 (1953).

${ }^{8}$ Merrifield and Woolley, $J$. Biol. Chem., 197, 521 (1952). Cohn and Markham, Proc. Biochem. Soc., 62, $17 p$ (1956)

${ }^{9}$ Brown, Heppel and Hilmoe, J. Chem. Soc., 40 (1954)

${ }^{10}$ Brown, Fried and Todd, J. Chem. Soc., 2206 (1955). Whitfeld, Biochem. J., 58, 390 (1954)

\section{Ionophoresis of Oligosaccharides as N-Benzylglycosylammonium lons}

Filter-PaPer ionophoresis is now being widely used for separations of mixtures of neutral sugars, which are converted into charged molecules by the formation of borate complexes ${ }^{1}$. This excellent method provides a far more rapid separation of isomeric components which possess appropriate structural differences than does filter-paper chromatography; and at the same time, deductions can be made about the probable structure of an unknown sugar from its rate of migration. It does, however, suffer from a disadvantage when compared with filter-paper chromatography, inasmuch as it does not give any indication of the molecular size of an unknown oligosaccharide. We now report a different method of filter-paper ionophoresis which readily yields this information; it is to be regarded as complementary to the borate process. When both methods are used in conjunction, much information about a new product can be gained very rapidly.

This alternative method of ionophoresis is a development of the technique of filter-paper chromatography in which reducing sugars are converted on the paper into $\mathrm{N}$-benzylglycosylamines ${ }^{2}$; in this case a charge is afterwards placed on the nitrogenous derivative by using a strongly acid solution as the medium during electrolysis. In the general method the reducing sugar is spotted on to a strip of Whatman No. 3 filter-paper, and a spot of a solution of benzylamine (1 c.c.) in methanol (9 c.c.) and $10 \mathrm{~N}$ formic acid (5 c.c.) is superimposed. The paper is heated at $95^{\circ}$ for $5 \mathrm{~min}$. and then subjecter to ionophoresis at $600 \mathrm{~V} . / 55 \mathrm{~cm}$. for $6 \mathrm{hr}$. in an electrolyte $(p \mathrm{H} \mathrm{1.8)}$ composed of a mixture of 5 per cent aqueous sodium hydroxide $(600$ c.c.) and 90 per cent formic acid (400 c.c.). The paper is dried to remove all formic acid, and the spots are detected with alkaline silver nitrate $^{3}$ or periodate ${ }^{4}$. The mobility is expressed as the ratio between the distance which separates the $\mathrm{N}$-benzylglycosylammonium ion from the unchanged sugar and the distance which separates the $\mathrm{N}$-benzylglucosylammonium ion from unchanged glucose. It is quite convenient to measure these distances because the reaction between the sugar and the benzylamine is

\begin{tabular}{lc}
\multicolumn{1}{c}{ Sugar } & Moble 1 \\
Pentose & $1 \cdot 09-1 \cdot 15$ \\
Hexose & $\mathbf{1} \cdot 00$ \\
Heptose & $0 \cdot 91$ \\
Hexose disaccharide & $0 \cdot 71-0 \cdot 78$ \\
Hexose trisaccharide & $0 \cdot 59-0 \cdot 63$ \\
Hexose tetrasaccharide & $0 \cdot 49-0 \cdot 51$ \\
Hexose pentasaccharide & $0 \cdot 42$ \\
Hexose hexasaccharide & $0 \cdot 33$ \\
\multicolumn{2}{c}{ * Defined in text. }
\end{tabular}

not complete (cf. ref. 2). Typical results are given in Table 1.

It will be seen that the mobility bears an inverse relationship to the molecular weight of the ion; to the first approximation, it is independent of the stereochemistry of the sugar and also of the positions of the linkages in a higher saccharide. Full details of this work, including the experiments which led to the development of the general method and studies with amines other than benzylamine, will be reported later. The work was supported by a grant from the Nuffield Foundation.

\section{S. A. BARKER \\ E. J. BOURNE* \\ P. M. Grant \\ M. STACEY}

Chemistry Department, University,

Birmingham 15. April 21.

* Present address: Royal Holloway College, University uf London, knglefield Green, Surrey.

1 koster, A. B., J. Chem. Soc., 982 (1953). Gross, D., Nature, 172, 908 (1953). Barker, G. R., and Smith, D. C. C., Chem. and Indust. 19 (1954). Gross, D., Nature, 173, $487(1954)$. Bell, D. J., and Northcote, D. H., Chem. and Indust., 1328 (1954). Foster, A. B., and Stacey, M., J. Chem. Soc., 1778 (1955). Gross, D., Nature, 176, $362(1955)$

Bayly, R. J., and Bourne, E. J., Nature, 171, 385 (1953).

'Trevelyan, W. E., Proctor, D. P., and Harrison, J. S., Nature, 166, $444(1950)$.

1 Gifonelli, J. A., and Smith, F., Anal. Chem., 26, 1132 (1954).

\section{Ion-Exchange Preparation of Low-Silica Hydroxide Solutions for Colorimetric Determinations of Total Silica}

AtTempts to determine small concentrations of total silica colorimetrically by applying the method of Straub and Grabowski ${ }^{1}$, following solubilization of the silica by boiling with hydroxide, have been frustrated by the interference of the silica present in either the sodium or potassium hydroxide used as the solubilizing agent. In studying this problem, the possibility of preparing a hydroxide solution by passing a salt solution through the hydroxide-form of a quaternary-base ion-exchange resin was investigated. The fact that complete conversion from the salt to the hydroxide is not required for the analytical method is a recommendation of this approach; a salt solution more concentrated than is normally amenable to ion-exchange treatment may be usert as the starting material in order to produce a moderately concentrated hydroxide solution.

A quaternary ammonium-type anion-exchange resin ('Amberlite $I R A-400$ ') was used in the preparation of the caustic solutions. A small column of the resin was prepared in a 1 - or 2 -in. diameter polyethylene pipe. The resin was converted to the hydroxide-form by treating it with six volumes/ volume resin of 4 per cent sodium bicarbonate solution followed by six volumes/volume resin of 4 per 